\title{
APLICABILIDADE DAS CINZAS DA CASCA DE ARROZ
}

Edson Luiz Foletto*, Ronaldo Hoffmann, Rejane Scopel Hoffmann, Utinguassú Lima Portugal Jr. e Sérgio Luiz Jahn Departamento de Engenharia Química, Centro de Tecnologia, Universidade Federal de Santa Maria, 97105-900 Santa Maria - RS

Recebido em 19/10/04; aceito em 29/3/05; publicado na web em 10/8/05

\begin{abstract}
APPLICABILITY OF RICE HUSK ASH. Currently, the accumulation of rice husk is a serious environmental problem. The burning of rice husk generates a considerable volume of ash, that falls to the ground and gets into the air and the rivers, causing a disequilibrium in the ecosystem. This motived research into solutions that aim to exploit the husks for energy generation and the ashes for developing diverse technological products. This work presents the possibilities of using rice husks and their ashes after burning.
\end{abstract}

Keywords: rice husk ash; rice husk; combustion.

\section{INTRODUÇÃO}

A utilização de fontes dispersas de energia, em particular a biomassa, aparece como uma oportunidade de singular importância, por colaborar na oferta de energia do sistema interligado do país. Trata-se de geração descentralizada e próxima aos pontos de carga, com equipamentos e combustível nacional (resíduos de processo). Existem várias formas de conversão da biomassa em energia, sendo que as mais utilizadas são combustão direta, gaseificação e pirólise. A questão ambiental, com a necessidade de minimização das emissões globais de $\mathrm{CO}_{2}$, é um ponto favorável ao uso da biomassa, pois quando esta é queimada, $\mathrm{CO}_{2}$ é liberado na atmosfera; entretanto, esse gás é absorvido pelas plantas durante a fotossíntese, mantendo constante a sua quantidade na atmosfera. Vantagens como estas fazem com que a biomassa seja uma opção estratégica para o país, só dependendo de políticas adequadas para sua viabilização. Vale ressaltar que os distintos cenários apresentados nas macrorregiões do país influenciam diretamente nos parâmetros de utilização da biomassa como energético. De maneira geral, a biomassa assim empregada enquadra-se perfeitamente no conceito do desenvolvimento sustentável, pois permite a criação de empregos na região, dinamiza as atividades econômicas, reduz os custos relativos à distribuição e transmissão da energia gerada e, quando utilizada de forma sustentável, não agride o meio ambiente.

Uma avaliação da distribuição da oferta de biomassa realizada, por ex., na Região Sul do Brasil ${ }^{1,2}$, demonstrou uma importante sobreposição de interesses: a oferta de biomassa está localizada exatamente onde se manifesta demanda reprimida de energia, fato que, por si só, elimina um importante problema existente na viabilização de centrais termelétricas à biomassa: o transporte de combustível. A produção de casca de arroz no mundo chega a 80 milhões de t ao ano. Isto representa, por ex., na Índia, uma produção de 22 milhões de $\mathrm{t}$ anuais, gerando $200 \times 10^{9} \mathrm{MJ}^{\mathrm{Me}}$ energia ${ }^{3}$. Somente no estado do Rio Grande do Sul foram produzidas 6,310 milhões de t de arroz na safra 2003/2004 ${ }^{4}$. Sabendo-se que as cascas representam $20 \%$ desse valor, a produção anual desse rejeito no Estado é da ordem de 1.162.000 t. Há alguns anos, quase todo

*e-mail: foletto@smail.ufsm.br esse material tinha como destino as lavouras e o fundo de rios, num descarte prejudicial e criminoso.

$\mathrm{Na}$ indústria do arroz temos, como subproduto mais volumoso, as cascas, as quais podem ser aproveitadas de diversas maneiras. A geração de energia através da queima da casca de arroz é uma alternativa praticável do ponto de vista tecnológico, viável do ponto de vista econômico e ética do ponto de vista ecológico, uma vez que existe tecnologia para a conversão, a matéria-prima é abundante na região e todo $\mathrm{CO}_{2}$ produzido na queima volta para o ciclo de carbono da biosfera terrestre. No caso da geração de energia pela combustão direta, o resíduo final é a cinza impura. Se ela for utilizada, direta ou indiretamente, para algum fim comercial, se fechará o ciclo da industrialização do arroz, sendo possível o total aproveitamento da matéria-prima proveniente da lavoura, já que o farelo, gérmen e outras partes já têm seu destino no mercado. Afinal, uma produção industrial ideal é aquela que gera resíduo zero. Se toda a casca de arroz disponível no Estado for queimada para geração de energia, a produção resultante, em termos de cinza pura, será de aproximadamente 209 mil t ao ano (cerca de $18 \%$ do peso da casca). Por outro lado, se essa cinza for descartada no meio ambiente, provocará poluição, pois se sabe que a cinza gerada na combustão apresenta uma certa quantidade de carbono residual, que é um grave poluente para o solo. Fica evidente que seu aproveitamento adequado resultará em benefício ao processo de conservação ambiental. Como a cinza contém alto teor de sílica (> 92\%), isto a torna um resíduo valorizado. № entanto essa cinza só terá alto valor econômico se tiver alta qualidade, que é mensurada pela alta superfície específica, tamanho e pureza de partícula. Conseqüentemente, seria um grande desperdício de matéria-prima nobre jogá-la fora, já que pode ser usada em vários ramos industriais, tais como eletrônica, construção civil, cerâmica, indústria química, fabricação de células fotovoltaicas, entre outros. Um grande número de usos para esses resíduos beneficiados têm sido relatados na literatura ${ }^{5}$.

Este trabalho teve como objetivo principal revisar os principais aspectos relacionados com o aproveitamento das cinzas de casca de arroz.

\section{ALTERNATIVAS TECNOLÓGICAS}

A seguir são descritas algumas alternativas para o aproveitamento das cinzas geradas na queima da casca de arroz. 


\section{Produção de carbeto de silício $(\mathrm{SiC})$}

Filamentos de $\mathrm{SiC}$ são usados como reforços para produção de cerâmicas resistentes e componentes de matrizes metálicas ${ }^{6}$. A natureza de durabilidade e resistência à fusão (material refratário) torna o $\mathrm{SiC}$ um material semicondutor muito desejado. Pesquisas estão desenvolvendo o $\mathrm{SiC}$ como um material para aplicações em avançados dispositivos de semicondutores. Eletrônicos e sensores à base de carbeto de silício podem operar em atmosferas hostis $\left(600{ }^{\circ} \mathrm{C}\right)$, onde eletrônicos convencionais à base de silício puro não podem (limite para $350{ }^{\circ} \mathrm{C}$ ), conferindo ao $\mathrm{SiC}$ uma larga utilização. Para obtenção do carbeto de silício são necessárias uma fonte de silício e uma fonte de carbono. Uma fonte barata de silício que pode ser utilizada é a cinza de casca de arroz. A síntese de SiC de cinzas de cascas de arroz foi iniciada por Lee e Cutler em $1975^{7}$. Há várias rotas que levam à transformação da casca do arroz em $\mathrm{SiC}^{8-15}$, mas elas têm como etapa essencial a pirólise da casca em temperaturas que variam entre $1200-2000{ }^{\circ} \mathrm{C}$, dependendo do processo. Os principais mecanismos na conversão de $\mathrm{SiC}$ de cinzas de casca de arroz podem ser representados pelas seguintes equações ${ }^{16,17}$ :

$\mathrm{SiO}_{2(\mathrm{~s})}+\mathrm{C}_{(\mathrm{s})} \rightarrow \mathrm{SiO}_{(\mathrm{g})}+\mathrm{CO}_{(\mathrm{g})}$

$\mathrm{SiO}_{2(\mathrm{~s})}^{2(\mathrm{~s})}+\mathrm{CO}_{(\mathrm{g})} \rightarrow \mathrm{SiO}_{(\mathrm{g})}+\mathrm{CO}_{2(\mathrm{~g})}$

$\mathrm{SiO}_{(\mathrm{g})}^{2(\mathrm{~s})}+2 \mathrm{C}_{(\mathrm{s})}^{(\mathrm{g})} \rightarrow \mathrm{SiC}_{(\mathrm{s})}^{(\mathrm{g})}+\mathrm{CO}_{(\mathrm{g}}$

$\mathrm{SiO}_{(\mathrm{g})}^{(\mathrm{g})}+3 \mathrm{CO}_{(\mathrm{g})} \rightarrow \mathrm{SiC}_{(\mathrm{s})}+2 \mathrm{CO}_{2(\mathrm{~g})}$

Geralmente a pirólise é feita em tubo de grafite com presença de fluxo de argônio para acelerar a produção de carbeto de silício e, também, evitar a oxidação. O uso de catalisadores é importante para que haja a formação de filamentos de $\mathrm{SiC}$, caso contrário formar-se-ía SiC na forma de partículas, que não é interessante para a indústria. A qualidade do carbeto de silício obtido é determinada por várias técnicas analíticas que avaliam morfologia, tamanho de partícula, composição química, estrutura eletrônica e modelos de vibração molecular. Krishnarao e Subrahmanyam ${ }^{6}$ produziram SiC a partir de uma mistura de casca de arroz e carvão, com e sem a presença do catalisador cobalto $\left(\mathrm{CoCl}_{2}\right)$, e observaram que com a presença do catalisador houve uma aceleração na formação do $\mathrm{SiC}$ filamentoso, ao passo que sem o Co o material formado apresentou-se na forma de partículas. $\mathrm{O}$ composto $\mathrm{Na}_{2} \mathrm{SiO}_{4}{ }^{18}$ mostrou ser um bom catalisador quando adicionado durante a pirólise da casca de arroz, pois diminuiu o tempo de formação de $\mathrm{SiC}$, enquanto que o composto $\mathrm{Si}_{3} \mathrm{~N}_{4}{ }^{19}$ aumentou o rendimento de $\mathrm{SiC}$ filamentoso. Han e $\mathrm{Liu}^{20}$ estudaram os produtos de vapor gerado durante a síntese de SiC e concluíram que estes gases residuais podem ser empregados na indústria, valorizando ainda mais o processo da transformação da cinza da casca de arroz em SiC.

\section{Produção de sílica pura}

A sílica é uma combinação de silício e oxigênio na forma $\mathrm{SiO}_{2}$. A cinza da casca de arroz pode conter até $15 \%$ em peso de carbono. Se o aquecimento for promovido com a finalidade de eliminar este carbono residual, pode-se obter aproximadamente $95 \%$ de sílica pura com uma área superficial específica de $10 \mathrm{~m}^{2} / \mathrm{g}$ e partículas com um tamanho em torno de $20 \mu \mathrm{m}$ gerando, assim, um produto de maior valor agregado. Jauberthie et al. ${ }^{21}$ demonstraram que a sílica é distribuída principalmente na epiderme externa da casca de arroz; no entanto outras partes da planta, onde perdas de água são elevadas, também contêm sílica. Sílica gel é a forma prevalecente de sílica em plantas de arroz. A sílica distribui-se entre os três principais componentes orgânicos: celulose, lignina e hemicelulose. Sílica gel pode ser usada como suporte para síntese em fase sólida, como purificador, catalisador ou reagente. As principais vantagens oferecidas por este material são suas condições simples de reação. A sílica pode ser classificada como aquagel (poros são preenchidos com água), xerogel (fase aquosa dos poros é removida por evaporação) e aerogel (solvente é removido por extração supercrítica). O xerogel tem várias aplicações como, por ex., estabilizar a cerveja. Para este fim o xerogel é produzido na forma de sílica amorfa, com função de adsorver seletivamente as proteínas ativas da cerveja. A sílica pode existir moída ou finamente moída (micromizada). Estes tipos de sílica são naturalmente brancos, com baixa umidade e quimicamente inertes. São usados em vários produtos que requerem um controle rígido das suas propriedades físico-químicas. A sílica micromizada é utilizada como carga e ampliador de formulações de tinta, conferindo maior resistência aos ataques químicos.

Alguns pesquisadores ${ }^{22-24}$ investigaram extensivamente a extração de sílica pura a partir da casca de arroz. A sílica gel, ou pó de sílica, pode ser obtida a partir de cinza de casca de arroz por um método simples que consiste, basicamente, em submeter cascas de arroz a um tratamento químico, geralmente utilizando ácido clorídrico, ácido sulfúrico ou hidróxido de sódio, seguida por aquecimento que varia de 600 a $800{ }^{\circ} \mathrm{C}$, dependendo do processo. A partir destes processos pode-se obter uma sílica de alta pureza, variando de 99,5 a $99,66 \%$ de $\mathrm{SiO}_{2}$ e com superfície específica elevada, caracterizando uma boa reatividade. Uma patente de processo de extração de sílica contida na casca e na planta de arroz foi depositada no INPI em nome de Souza et al. ${ }^{25}$. Della et al. ${ }^{26}$ obtiveram cinzas com cerca de $97 \%$ de $\mathrm{SiO}_{2}$ e observaram que a cinza apresentava características refratárias, indicativo de um material em potencial para fabricação de tijolos refratários como os necessários em fornos siderúrgicos.

Segundo $\operatorname{Real}^{23}$, o baixo valor da área específica $\left(<1 \mathrm{~m}^{2} / \mathrm{g}\right)$ obtida por calcinação direta da casca, sem a lavagem ácida, ocorre devido à presença de impurezas como $\mathrm{K}^{+}$, pois esses íons podem se alojar nas cavidades da estrutura de $\mathrm{SiO}_{2}$. A presença de íons $\mathrm{K}^{+}$na casca de arroz também faz acelerar a fusão de partículas e a cristalização de $\mathrm{SiO}_{2}$ amorfa para cristobalita ( $\mathrm{SiO}_{2}$ cristalina). Sílica na forma de pó pode ser obtida utilizando-se a tecnologia de leito fluidizado ${ }^{27,28}$. A sílica gel obtida pelos processos acima pode ser transformada em xerogel passando por mais um processo de aquecimento. Silicatos solúveis produzidos a partir de sílica são largamente usados em vidros, cerâmicas, cimento, em produtos farmacêuticos, cosméticos e detergentes industriais (como cola e agente adesivo).

Vários outros trabalhos visando a obtenção de sílica com alto grau de pureza por diferentes rotas, a partir de cinzas de casca de arroz, são citados na literatura ${ }^{29-33}$.

\section{Utilização da cinza como carga em polímeros}

A cinza de casca de arroz pode ser utilizada como carga de reforço em compostos de borracha natural, em substituição a outros materiais, para promover melhores propriedades mecânicas como tensão, dureza, elongação e acréscimo de massa fornecendo, assim, um composto de borracha com melhor desempenho. Um dos primeiros trabalhos preliminares sobre o uso de cinzas de casca de arroz como carga em polímeros foi reportado em 1975 por Haxo e Mehta ${ }^{34}$, e o uso dessa carga em polietileno foi reportado recentemente por Fuad et al. ${ }^{35}$, que observaram um aumento significativo no módulo de flexão do compósito, sendo comparável ao de outras cargas comerciais utilizadas, como por ex., a mica. Entretanto, Ishak e Bakar $^{36}$ foram os primeiros que sugeriram a utilização tecnológica de cinzas de casca como carga de borracha. Eles usaram cinzas de casca de arroz nas variedades branca e preta como 
carga em elastômeros, especificamente, em borracha natural epoxidada, e observaram que a cinza branca exibiu melhores propriedades físicas em relação à preta, mas não muito menor quando comparada com cargas comerciais como carvão e sílica. Dependendo de como a cinza é gerada, duas variedades são produzidas, as quais diferem principalmente no percentual em sílica. A cinza branca origina-se a temperaturas maiores e é quase totalmente composta por sílica, enquanto a cinza preta, formada a temperaturas mais baixas, contém, além da sílica, uma boa quantidade de material orgânico.

Em outro trabalho ${ }^{37}$, um aumento do teor de cinzas de casca de arroz como carga numa blenda polimérica formada por borracha natural e polietileno de baixa densidade resultou na redução da resistência à tração, elongação e na densidade, porém no aumento da dureza e do módulo de elasticidade. Com a adição de um compatibilizador [poli(propileno-etileno-ácido acrílico)], observouse um aumento na resistência à tração, dureza e elongação, mas uma redução na densidade ${ }^{38}$. O uso de cinzas de casca de arroz como carga na preparação de um material elastomérico baseado em poli(metilvinil siloxano) mostrou ser promissor na função de evitar a seletividade e permeabilidade de gases oxigênio, nitrogênio, dióxido de carbono e metano, devido à melhoria nas propriedades mecânicas do elastômero ${ }^{39}$. As cinzas foram também usadas como carga em resinas de poliéster ${ }^{40}$.

\section{Produção de cimento e uso em concreto}

O uso da cinza de casca de arroz como fonte de sílica no cimento diminui a resistência à compressão, aumenta a durabilidade do concreto e reduz a porosidade, o que é extremamente importante em muitas aplicações, tais como canais de irrigação, concretos resistentes à poluição e às intempéries, pisos resistentes à abrasão, etc. Várias pesquisas mostram que o cimento pode ser produzido a partir de cinza de casca de arroz com sucesso, devido ao seu baixo custo em substituição à areia. Ajiwe et $a l .{ }^{41}$ produziram cimento com cinza de casca de arroz variando a porcentagem de cinza na formulação do cimento entre 23-26\%, concluindo que o melhor é 24,5\%. Ismail e Waliuddin $^{42}$ analisaram os efeitos da cinza da casca de arroz no concreto e através de experimentos com diferentes composições de cinza constataram que é possível produzir um concreto com alta resistência à compressão, porém menor comparada à obtida com o uso de cimento. Weber ${ }^{43}$ observou que o uso da cinza de casca de arroz na obtenção de concreto e argamassa mostrou-se economicamente vantajoso, pela sua demanda inferior de água necessária para atingir uma dada consistência. Kilinçkale ${ }^{44}$ estudou a durabilidade do concreto produzido por adição de agentes pozolânicos como cinzas de casca de arroz. Zhang et al..$^{45}$ compararam o concreto feito com cimento Portland e com o cimento contendo cinzas de casca de arroz, concluindo que ambos apresentaram resistência à compressão semelhantes. Cisse e Laquerbe ${ }^{46}$ avaliaram as características mecânicas do preenchimento de areia em concretos com cinza da casca de arroz e concluíram que a adição da cinza melhora as propriedades físicas e mecânicas do cimento. Isaia ${ }^{47}$ investigou a adição de cinza de casca de arroz e microssílica em concreto de alto desempenho, objetivando verificar a durabilidade com vistas à corrosão da armadura. Zhang e Malhotra ${ }^{48}$ avaliaram as propriedades físicas e químicas da cinza de casca de arroz incorporada ao concreto, bem como o desempenho desta cinza no concreto fresco e endurecido. Eles analisaram concretos contendo cinzas e concretos com cimento Portland, e observaram que ambos indicaram resultados semelhantes com relação às propriedades de resistência à flexão e cisalhamento, módulo de elasticidade e retração, porém o concreto com cinza mostrou excelente resistência à penetração de cloretos. As cinzas propiciaram uma melhoria do concreto frente ao ataque ácido ${ }^{49}$ e também foram utilizadas no processo de moldagem a verde, em fundição ${ }^{50}$. O efeito de $3 \%$ (em peso) de álcool polivinílico sobre a hidratação do cimento Portland na presença e ausência de $10 \%$ de cinzas de casca de arroz foi estudado ${ }^{51}$, e os resultados mostraram que as duas amostras de cimento apresentaram comportamento similar quanto à resistência e diminuição da porosidade do concreto, e com isso, a substituição de parte do cimento por $10 \%$ de cinza torna-se justificável economicamente.

A literatura apresenta inúmeros trabalhos utilizando cinzas de casca de arroz para produção de concreto e sua influência sobre as propriedades do mesmo ${ }^{52-63}$.

\section{Uso de cinzas como adsorventes}

A indústria de extração do ouro freqüentemente usa cianeto como agente lixiviante do ouro. No entanto, há casos em que o processo de cianetação apresenta limitações ou dificuldades tecnológicas, as quais podem inviabilizar economicamente sua aplicação ${ }^{64}$. A tiouréia $\left(\mathrm{NH}_{2} \mathrm{CSNH}_{2}\right)$ tem sido um reagente alternativo ao cianeto, por não ser tão tóxico quanto o cianeto e por apresentar altas taxas de lixiviação, porém, a sua utilização ainda necessita de mais desenvolvimento na recuperação do ouro, visando minimizar o consumo de tiouréia e seu custo de produção. Nos casos de soluções de ouro de baixa concentração, o processo de pré-concentração é essencial antes da separação do mesmo. Geralmente, utiliza-se carvão ativado para processos de pré-concentração, mas esse adsorvente apresenta como desvantagens a adsorção de tiouréia livre e uma maior dificuldade de separação do ouro do complexo ouro-tiouréia $\left[\mathrm{AuCS}\left(\mathrm{NH}_{2}\right)_{2}\right]^{+}$ ${ }^{65,66}$. Neste sentido, Nakbanpote et al. ${ }^{67}$ usaram carvão ativado e cinzas de casca de arroz como adsorventes para pré-concentrar o ouro, sendo que a cinza apresentou uma menor habilidade em adsorver o complexo de ouro-tiouréia quando comparada com o carvão ativado. Por outro lado, apresentou um maior rendimento na remoção do ouro adsorvido. A pesquisa revelou também que a melhor cinza para ser usada como adsorvente foi aquela obtida pela queima da casca de arroz a $300{ }^{\circ} \mathrm{C}$, pois nesta temperatura o resíduo apresentou propriedades de troca iônica. Outras alternativas de adsorvente são as resinas de troca de cátion, promovendo uma boa recuperação do complexo de ouro-tiouréia, com menor consumo de tiouréia e mais fácil remoção se comparado ao carvão ativado. No entanto, a resina de troca de cátion é relativamente cara.

Tarley e Arruda ${ }^{68}$ utilizaram casca de arroz in natura para remoção de metais pesados ( $\mathrm{Al}, \mathrm{Cd}, \mathrm{Cu}, \mathrm{Pb}$ e $\mathrm{Zn}$ ) presentes em efluentes sintéticos. A casca de arroz, utilizada nos ensaios de adsorção, foi moída e passada por peneira para obtenção de partículas menores que $355 \mu \mathrm{m}$. Os resultados dos teores de metais determinados nos efluentes ficaram abaixo daqueles requeridos pela EPA ("Environmental Protection Agency") para descarte de efluentes.

Feng et al. ${ }^{69}$ usaram cinzas de casca de arroz como adsorventes de chumbo e mercúrio de águas residuárias. As cinzas foram obtidas pela lixiviação das cascas de arroz com $\mathrm{HCl} 1 \mathrm{~mol} / \mathrm{L}$ por $4 \mathrm{~h}$ e, subseqüente calcinação a $700{ }^{\circ} \mathrm{C}$ por $4 \mathrm{~h}$. Os estudos de adsorção foram realizados com soluções aquosas de mercúrio e chumbo, preparadas de $\mathrm{Hg}\left(\mathrm{NO}_{3}\right)_{2}$ e $\mathrm{Pb}\left(\mathrm{NO}_{3}\right)_{2}$, respectivamente. Estudou-se a influência das seguintes variáveis na adsorção dos metais: força iônica, tamanho das partículas de cinzas e pH da solução. Solução de nitrato de potássio em diferentes concentrações $(0,0001$ a $1 \mathrm{~mol} / \mathrm{L})$ foi usada para ajuste da força iônica nas soluções de $\mathrm{Hg}$ e $\mathrm{Pb}$. As frações de partículas testadas foram menores que $43 \mu \mathrm{m}, 43-74$ $\mu \mathrm{m}, 74-175 \mu \mathrm{m}$ e maiores que $175 \mu \mathrm{m}$. O pH de cada solução foi ajustado com $0,5 \mathrm{~mol} / \mathrm{L}$ de $\mathrm{NaOH}$ ou $\mathrm{HCl}$. Os resultados mostra- 
ram que a retenção dos metais nas cinzas, usadas como adsorventes, foi favorecida com a diminuição do tamanho de partículas, com o aumento do $\mathrm{pH}$ da solução e com a diminuição da concentração de eletrólitos (solução de nitrato de potássio). Outros usos de cinzas de casca de arroz têm sido citados na literatura com fins adsortivos como por ex., na remoção de mercúrio de efluentes ${ }^{70}$, na remoção de ácidos graxos livres em óleo de soja ${ }^{71,72}$ e em estudos de adsorção de cobre, níquel e zinco em soluções sintéticas ${ }^{73}$.

\section{Uso de cinza como suporte de catalisadores metálicos}

Chang et $a l .{ }^{74}$ utilizaram cinza de casca de arroz (sílica amorfa) como suporte para preparação de catalisadores à base de níquel. Estes materiais são freqüentemente usados em reações catalíticas, como metanação de $\mathrm{CO}$ e $\mathrm{CO}_{2}$, hidrogenação de óleos insaturados, reação de reforma à vapor e hidrogenação de hidrocarbonetos aromáticos. Neste trabalho, a cinza de casca de arroz foi obtida por tratamento ácido $(\mathrm{HCl} 3 \mathrm{~mol} / \mathrm{L})$ e por pirólise em atmosfera de nitrogênio $\left(900{ }^{\circ} \mathrm{C}\right.$ por $1 \mathrm{~h}$ ). $\mathrm{O}$ catalisador de níquel suportado nas cinzas foi obtido pela técnica de impregnação a úmido, podendo ser preparado também por troca iônica ${ }^{75,76}$. O catalisador foi usado na reação de metanação de $\mathrm{CO}_{2}$ (mistura de $\mathrm{H}_{2} / \mathrm{CO}_{2}=4 / 1$ ) e apresentou alta seletividade (80$90 \%$ ) para formação do metano. A conversão de $\mathrm{CO}_{2}$ e a formação de $\mathrm{CH}_{4}$ foram dependentes das condições de calcinação da casca de arroz na obtenção das cinzas. O valor máximo atingido para formação de $\mathrm{CH}_{4}$, na reação de metanação, foi à temperatura de $500{ }^{\circ} \mathrm{C}$.

Os mesmos pesquisadores prepararam e caracterizaram um composto formado por cinzas de casca de arroz e alumina como suporte de níquel ${ }^{77,78}$ e testaram na mesma reação. Em um outro trabalho ${ }^{79}$, esses pesquisadores prepararam e compararam o catalisador de níquel suportado no composto cinza/ $/ \mathrm{Al}_{2} \mathrm{O}_{3}$ e no composto $\mathrm{SiO}_{2} / \mathrm{Al}_{2} \mathrm{O}_{3}$ para a reação de hidrogenação do $\mathrm{CO}_{2}$ e observaram que o primeiro apresentou um melhor desempenho na conversão e seletividade à $\mathrm{CH}_{4}$, na temperatura de $500{ }^{\circ} \mathrm{C}$.

As cinzas de casca de arroz também foram usadas na preparação de catalisadores de cobre para uso na reação de desidrogenação de etanol $^{80}$. O composto nitrato de cobre triidratado foi usado para impregnação de cobre no suporte. A conversão de etanol foi fracamente dependente do teor de cobre impregnado, mas foi dependente da temperatura de reação, aumentando com o aumento desta. A atividade catalítica do cobre suportado sobre cinzas de casca de arroz foi superior à do cobre suportado sobre sílica gel.

\section{Síntese de zeólitas}

As zeólitas são aluminossilicatos cristalinos microporosos, com uma estrutura baseada numa extensa rede tridimensional. Seus microporos (ou canais) têm dimensões fixas, determinadas pela estrutura, abrangendo em geral uma faixa de 3 a $13 \AA^{81}$. As cavidades são ocupadas por íons e moléculas de água com considerável liberdade de movimento, podendo sofrer troca iônica e desidratação reversível. A estrutura é constituída por uma cadeia de tetraedros $\mathrm{SiO}_{4}$ e $\mathrm{AlO}_{4}^{-}$, nos quais os átomos de silício e alumínio ocupam o centro dos tetraedros, sendo estes últimos ligados entre si pelo compartilhamento dos átomos de oxigênio. Os íons de carga positiva neutralizam a carga elétrica negativa da rede, resultante da tetracoordenação do átomo de alumínio. A quantidade de cátions que uma zeólita pode trocar com o ambiente depende de sua composição química, ou mais precisamente do teor de alumínio, pois é decorrente da presença deste elemento que a rede é desbalanceada, necessitando de um cátion compensador de carga.

As zeólitas sintéticas podem ser obtidas por cristalização, sob condições hidrotérmicas, de meios reacionais que contenham os ele- mentos necessários à edificação da estrutura desejada, que são fontes de $\mathrm{SiO}_{2}, \mathrm{Al}_{2} \mathrm{O}_{3}$, cátions, $\mathrm{OH}^{-}$e $\mathrm{H}_{2} \mathrm{O}$. Neste caso, a cinza de casca de arroz, por possuir elevados teores de silício, pode ser utilizada como fonte deste elemento na preparação de zeólitas. Wang et al. ${ }^{82}$ realizaram a síntese da zeólita ZSM-48 empregando cinza de casca de arroz como fonte de sílica e aplicaram este material como catalisador para craqueamento do n-hexano. Em outros estudos, preparou-se a zeólita ZSM-5 ${ }^{83-85}$ a partir de cinzas de casca de arroz como fonte de sílica, e esta apresentou atividade catalítica para a reação de hidrogenação do $\mathrm{CO}_{2}$ comparável à ZSM-5 obtida com sílica comer$\mathrm{cial}^{83}$. Cinzas de casca de arroz também foram utilizadas para síntese de zeólitas do tipo mordenita ${ }^{86}, \mathrm{NaX}^{87}, \mathrm{Y}^{88}$ e $4 \mathrm{~A}^{89}$.

Foi possível cristalizar zeólitas com estrutura do tipo LTA ("Linde type A") à temperatura de $100{ }^{\circ} \mathrm{C}$, com $3 \mathrm{~h}$ de cristalização e composição molar do meio reacional igual a $\mathrm{Al}_{2} \mathrm{O}_{3}: 2,1 \mathrm{SiO}_{2}: 3,9 \mathrm{Na}_{2} \mathrm{O}: 35,2 \mathrm{H}_{2} \mathrm{O}$ ${ }^{90}$. Por apresentar alta capacidade de troca catiônica (CTC) este tipo de zeólita pode ser utilizado para acondicionar nutrientes como nitrogênio (na forma $\left.\mathrm{NH}_{4}^{+}\right)$, potássio $\left(\mathrm{K}^{+}\right)$, magnésio $\left(\mathrm{Mg}^{2+}\right)$, cálcio $\left(\mathrm{Ca}^{2+}\right)$ e traços de micronutrientes como $\mathrm{Ni}^{2+}, \mathrm{Mo}^{2+}, \mathrm{Cu}^{2+}, \mathrm{Mn}^{2+}$, etc. Essa zeólita pode ser incorporada a solos, para a liberação lenta destes nutrientes, reduzindo a perda de fertilizantes e nutrientes por lixiviação, resultando em menores danos ao meio ambiente. É largamente utilizada como adsorvente na formulação de detergentes, para captura de cátions em água de formulação, em substituição aos fosfatos, que agridem o meio ambiente $\mathrm{e}^{91,92}$.

Jahn et al. ${ }^{93}$ sintetizaram a zeólita A usando um sistema reacional fechado, usando $\mathrm{NaOH}$ como agente mineralizante, nas concentrações de 3 a 12 mol/L, com tempo reacional de 3 a 12 h. Esses materiais apresentaram altos valores de capacidade de troca catiônica (4-5 meq/g), sendo comparáveis e superiores aos valores encontrados na literatura para outras zeólitas, que vão de 3 a 4 meq/g mostrando, com isso, que esse material também possui potencial adsortivo.

\section{Produção de diferentes tipos de silicatos}

Mulita $\left(3 \mathrm{Al}_{2} \mathrm{O}_{3}: 2 \mathrm{SiO}_{2}\right)$ é um aluminossilicato que raramente ocorre na natureza como mineral. Foram encontradas ocorrências naturais apenas na costa da Inglaterra, sendo sua formação rara na natureza porque resulta do contato de minerais de aluminosilicato exatamente do mesmo tipo a temperaturas extremamente altas. A mulita é um bom isolante térmico e elétrico, até mesmo em altas temperaturas e, também, muito resistente em ambientes corrosivos. Em resumo, a mulita é um ingrediente chave em muitos produtos refratários e cerâmicos ${ }^{94}$.

A sílica pura obtida a partir da casca de arroz, com uma área de superfície de 260 a $480 \mathrm{~m}^{2} / \mathrm{g}$ e pureza em torno de $99 \%$, pode ser utilizada para preparação de filamentos de mulita, empregada em técnicas de vidro aluminosilicato raramente encontrados na natureza. Sabe-se que é possível obter corpos de mulita de grande pureza a partir de rejeitos industriais de hidróxido de alumínio e da sílica da casca de arroz. Procurando se beneficiar da reatividade da sílica obtida da casca de arroz e do pequeno tamanho das partículas de hidróxido de alumínio, Souza e Yamamoto ${ }^{95}$ sintetizaram a mulita e a cordierita $\left(\mathrm{Mg}_{2} \mathrm{Al}_{4} \mathrm{~S}_{\mathrm{i} 5} \mathrm{O}_{18}\right)$ com baixíssimo teor de fase líquida. Em outro trabalho ${ }^{96}$, esses pesauisadores procuraram diminuir a temperatura de formação da mulita via formação de géis. A cordierita possui propriedades refratárias, baixa expansão térmica, e é usada como suporte para catalisadores de gases de exaustão em automóveis, em fornos industriais, podendo ser sintetizada a partir de cinzas de casca de arroz como fonte de silício ${ }^{97}$.

A cinza da casca de arroz (como partículas pequenas, de distribuição entre 2 e $7 \mu \mathrm{m}$ ) reage com catecol e metóxido de sódio em metanol para produzir tri(catecolato)silicato, $\mathrm{Na}\left[\mathrm{Si}\left(\mathrm{O}-\mathrm{C}_{6} \mathrm{H}_{4} \mathrm{O}_{2}\right)_{3}\right]$. 
A sílica proveniente das cinzas da casca de arroz tem sido usada para preparação de glicolatos reativos e silicatos de catecolatos, por serem fontes acessíveis e baratas de silício $^{98}$. Jahn et al. ${ }^{99}$ produziram silicato de sódio a partir de uma mistura reacional de sílica da casca de arroz e hidróxido de sódio comercial. Eles observaram que, após 3 h de reação na temperatura de $100{ }^{\circ} \mathrm{C}$ e com as seguintes composições iniciais: $\mathrm{Na}_{2} \mathrm{O} / \mathrm{SiO}_{2}=1, \mathrm{H}_{2} \mathrm{O} / \mathrm{SiO}_{2}=22$, o rendimento de dissolução do silício foi de $83 \%$ e concluíram que o rendimento é favorecido usando temperaturas superiores a $100{ }^{\circ} \mathrm{C}$.

\section{CONSIDERAÇÕES FINAIS}

A tendência do aproveitamento integral de resíduos é uma necessidade cada vez maior na indústria moderna, devido à crise energética mundial e à busca de fontes alternativas de energia renovável. Neste sentido, as cascas residuais oriundas dos engenhos de beneficiamento de arroz vêm sendo utilizadas como combustível, visando o aproveitamento energético. Quando não queimadas, são descartadas no meio ambiente, em terrenos baldios ou em mananciais, provocando poluição ambiental. Do processo de queima das cascas de arroz sobram, ainda, as cinzas, cujo destino está em aberto. A casca de arroz é o resíduo vegetal que mais produz cinzas quando queimada. Essas cinzas, por serem compostas basicamente de sílica, podem ser utilizadas como matéria-prima na elaboração de diversos materiais, em diferentes ramos industriais, tais como o da construção civil, cerâmica e de vidros.

Nos últimos anos, tem-se investido cada vez mais em pesquisas para transformação das cinzas de casca de arroz, até então consideradas resíduos industriais, em subproduto de interesse comercial.

\section{REFERÊNCIAS}

1. Hoffmann, R.; Tese de Doutorado, Universidade Federal do Rio Grande do Sul, Brasil, 1999.

2. Pretz, R.; Tese de Doutorado, Universidade Federal do Rio Grande do Sul, Brasil, 2001.

3. Natarajan. E.; Ohman, M.; Gabra, M.; Nordin, A.; Liliedahl, T.; Rao, A. N.; Biomass and Bioenergy 1998, 15, 163.

4. http://www.irga.rs.gov.br, acessada em Outubro 2004.

5. Houston, D. F.; Rice Chemistry and Technology, American Association of Cereal Chemists, Inc., St. Paul: USA, 1972.

6. Krishnarao, R. V.; Subrahmanyam, J.; Ceram. Int. 1995, 22, 489.

7. Lee, J. G.; Cutler, I. B.; J. Am. Ceram. Soc. Bull. 1975, 54, 195.

8. Mansour, N. A.; Hanna, S.B.; J. Brit. Ceram. Soc. 1979, 68, 132.

9. Bechtold, B. C.; Beatty, R. I.; Cook, J. L. Em Science and Engineering Composites; Hayashi, T.; Kawata, K.; Umekawa, S., eds.; ICCM-IV, Tokyo: Japan, 1982.

10. Lakiza, S. N.; Dyban, Y. U. P.; Sov. Power Metall. Met. Ceram. 1982, 21, 117.

11. Sharama, N. K.; Williams, W. S.; Zangvil, A.; J. Am. Ceram. Soc. 1984, 67,715 .

12. Martinell, J. R.; Roberto, J.; Helena, A. B.; Ceramicia 1989, 35, 162.

13. Patel, M.; Kareera, A.; J. Mater. Sci. Lett. 1989, 8, 955.

14. Krishnarao, R. V.; Godkhindi, M. M.; Chakraborty, M.; Mukunda, P. G.; J. Am. Ceram. Soc. 1991, 74, 2869.

15. Krishnarao, R. V.; Godkhindi, M. M.; J. Mater. Sci. Lett. 1992, 27, 1227.

16. Shimokawa, K.; Sekiguchi, I.; Ueda, Y.; J. Ceram. Soc. Jpn. 1992, 100, 1111.

17. Krishnarao, R. V.; Subrahmanyam, J.; Ceram. Int. 1996, 22, 489.

18. Janghorban, K.; Tazesh, H. R.; Ceram. Int. 1999, 25, 7.

19. Krishnarao, R. V.; Godkhindi, M. M.; Ceram. Int. 1992, 18, 185.

20. Han, H.-W.; Liu, H.-S.; Ceram. Int. 1999, 25, 631.

21. Jauberthie, R.; Rendell, F.; Tamba, S.; Cisse, I.; Construction and Building Materials 2000, 14, 419 .

22. Kalapathy, U.; Proctor, A.; Shultz, J.; Bioresour. Technol. 2000, 73, 257

23. Real, C.; J. Am. Ceram. Soc. 1996, 79, 2012.

24. Yalçin, N.; Sevinç, V.; Ceram. Int. 2001, 27, 219.

25. Souza, M. F.; Libório, J. B. L.; Batista, P. S.; INPI patente PI9903208-2, 1999.
26. Della, V. P.; Kühn, I.; Hotza, D.; Quim. Nova 2001, 24, 778.

27. Huang, S.; Jing, S.; Wang, J.; Wang. Z.; Jin, Y.; Powder Technol. 2001, $117,232$.

28. Fang, M.; Yang, L.; Chen, G.; Shi, Z.; Luo, Z.; Cen, K.; Fuel Process. Technol. 2004, 85, 1273.

29. Armesto, L.; Bahillo, A.; Veijonen, K.; Cabanillas, A.; Otero, J.; Biomass and Bioenergy 2002, 23, 171.

30. Bose, D. N.; Govindacharyulu, P. A.; Banerjee, H. D.; Sol. Energy Mater. Sol. Cells 1982, 7, 319.

31. Banerjee, H. D.; Sem, H. S.; Mater. Sci. Eng. 1982, 52, 173.

32. James, J.; Rao, M. S.; Thermochim. Acta 1986, 97, 329.

33. Della, V. P.; Kühn, I.; Hotza, D.; Mater. Lett. 2002, 57, 818

34. Haxo, H. E.; Mehta, P. K.; Rubber Chem. Technol. 1975, 48, 71.

35. Fuad, M. Y. A.; Ismail, Z.; Mansor, M. S.; Ishak, M. Z.; Omar, M. K.; Polym. J. 1995, 27, 1002.

36. Ishak, M.; Bakar, A. A.; Eur. Polym. J. 1995, 31, 259.

37. Ismail, H.; Nizam, J. M.; Khalil, H. P. S. A.; Eur. Polym. J. 1999, 35, 1429.

38. Ismail, H.; Nizam, J. M.; Khalil, A.; Polym. Test. 2001, 20, 125.

39. Sereda, L.; L.-González, M. M.; Visconte, L L. Y.; Nunes, R. C. R.; Furtado, C. R. G.; Riande, E.; Polymer 2003, 44, 3085.

40. Chand, N.; Dan, T. K.; Verma, S.; Rohatgi, P. S.; J. Mater. Sci. Lett. 1987, 6, 733.

41. Ajiwe, V. I. E.; Okeke, C. A.; Akigwe, F. C.; Bioresour. Technol. 2000, 73, 37.

42. Ismail, M. S.; Waliuddin, A. M.; Construction and Building Materials 1996, 10,521

43. Weber, S.; Dissertação de Mestrado, Universidade Federal de Santa Catarina, Brasil, 2001.

44. Kilinçkale, F. M.; Cem. Concr. Res. 1997, 27, 1911.

45. Zhang, M. H.; Lastra, R.; Malhotra, V. M.; Cem. Concr. Res. 1996, 26, 963.

46. Cisse, I. K.; Laquerbe, M.; Cem. Concr. Res. 2000, 30, 13.

47. Isaia, G. C.; Tese de Doutorado, Universidade de São Paulo, Brasil, 1995.

48. Zhang, M. H.; Malhotra, V. M.; Proceedings of the $5^{\text {th }}$ Canmet/ACI International Conference on Fly Ash, Silica Fume, Slag and Natural Pozzalans in Concrete, Wisconsin, Canadá, 1995.

49. Sugita, S.; Proceedings of the $10^{\text {th }}$ International Congress on the Chemistry of Cement, Gothenburg, 1992.

50. Just, M. L.; Dissertação de Mestrado, Universidade Federal de Santa Maria, Brasil, 2001.

51. Singh, N. B.; Rai, S.; Cem. Concr. Res. 2001, 31, 239.

52. Feng, Q.; Yamamichi, H.; Shoya M.; Sugita, S.; Cem. Concr. Res. 2004, 34,521 .

53. Nehdi, M.; Duquette, J.; Damatty, A.; Cem. Concr. Res. 2003, 33, 1203.

54. Nehdi, M.; Damatty, A.; Rahimi, R.; Int. J. Adhes. Adhes. 2003, 23, 323.

55. Rahman, M. A.; Int. J. Cem. Comp. Lightweight Concr. 1987, 9, 105.

56. Yogananda, M. R.; Jagadish, K. S.; Building Environ. 1988, 23, 303.

57. Salas, J.; Alvarez, M.; Veras, J.; J. Cem. Comp. Lightweight Concr. 1987, 9, 177.

58. Santos, S.; Dissertação de Mestrado, Universidade Federal de Santa Catarina, Brasil, 1997.

59. Dafico, D. A.; Dissertação de Mestrado, Universidade Federal de Santa Catarina, Brasil, 2001.

60. Guedert, L. O.; Dissertação de Mestrado, Universidade Federal de Santa Catarina, Brasil, 1989.

61. Vaghetti, M. A.; Dissertação de Mestrado, Universidade Federal de Santa Maria, Brasil, 1999.

62. Winck, M. L.; Dissertação de Mestrado, Universidade Federal de Santa Maria, Brasil, 2002.

63. Moraes, R. C.; Dissertação de Mestrado, Universidade Federal de Santa Maria, Brasil, 2001.

64. http://www.cetem.gov.br/publicacao/extracao_de_ouro/capitulo_09.pdf, acessada em Fevereiro 2004

65. Juarez, C. M.; Oliveira, J. F.; Miner. Eng. 1993, 6, 575.

66. Deschenes, G.; Ritcey, G. M.; U.S. pat. 4,913,730 1990.

67. Nakbanpote, W; Thiravetyan, P.; Kalambaheti, C.; Miner. Eng. 2000, 13, 391.

68. Tarley, C. R. T.; Arruda, M. A. Z.; Chemosphere 2004, 54, 987.

69. Feng, Q.; Lin, Q., Gong, F.; Sugita, S.; Shoya, M.; J. Colloid Interface Sci. 2004, 278, 1.

70. Tiwari, D. P.; Singh, D. K.; Saksena, D. N.; J. Environ. Eng. 1995, 121, 479.

71. Proctor, A .; Palaniappan, S.; JAOCS 1990, 61, 15.

72. Liew, K. Y.; Yee, A. H.; Nordin, M. R.; JAOCS 1993, 70, 539.

73. Said, O. B.; Shalmor, M. B.; Egila, J. N.; Bioresour. Technol. 1993, 43, 63.

74. Chang, F.-W.; Hsiao, T.-J.; Chung, S.-W.; Lo, J.; Appl. Catal., A 1997, 164, 225 . 
75. Tsay, M.-T.; Chang, F.-W.; Appl. Catal., A 2000, 203, 15.

76. Chang, F.-W.; Tsay, M.-T.; Kuo, M.-S.; Yang, C.-M.; Appl. Catal., A 2002, 226, 213.

77. Tsay, M.-T.; Chang, F.-W.; Catal. Commun. 2001, 2, 233.

78. Chang, F.-W.; Tsay, M.-T.; Kuo, M.-S.; Thermochim. Acta 2002, 386, 161.

79. Chang, F.-W.; Kuo, M.-S.; Tsay, M.-T.; Hsieh, M.-C.; Appl. Catal., A 2003, 247, 309.

80. Chang, F.-W.; Kuo, M.-S.; Lee, K.-C.; Appl. Catal., A 2003, 246, 253.

81. Barrer, R. M.; Hydrothermal chemistry of Zeolites, Academic Press: Londres, 1982

82. Wang, H. P.; Lin, K. S.; Huang, Y. J.; Li, M. C.; Tsaur, L. K.; J. Hazard. Mater. 1998, 58,

83. Chareonpanich, M.; Namto, T.; Kongkachuichay, P.; Limtrakul, J.; Fuel Process. Technol. 2004, 85, 1623.

84. Rawtani, A. V.; Rao, M. S.; Gokhale, K. V. G. K.; Ind. Eng. Chem. Res. 1989, 9, 1411.

85. Kumar, N. L.; Das, D.; Research and Industry 1992, 37, 141.

86. Bajpai, P. K.; Rao, M. S. Gokhale, K.; Ind. Eng. Chem. Res Develop. 1981, 20, 721

87. Dalai, A. K.; Rao, M. S.; Gokhale, K.; Ind. Eng. Chem. Res. Develop. 1985, $24,465$.

88. Hamdan, H.; Keat, Y. A.; Malaysian Patent 450/1/4-22, 1993
89. Deabriges, J.; U.S. pat. 4,314,979 1982; Bretaudea, U.; U.S. pat. 5,474,753 1995; Krummel, K.; U.S. pat. 3,985,669 1976.

90. Castoldi, M. C. M.; Dissertação de Mestrado, Universidade Federal de Santa Maria, Brasil, 2003

91. Strack, H.; U.S. pat. 4,303,629 1981.

92. Allen, H. E.; Cho, S. H.; Neubecker, T. A.; Water Res. 1983, 17, 1871.

93. Jahn, S. L.; Castoldi, M. C. M.; Soares, E. T.; Fiorentini, I.; Hoffmann, R.; Portugal Jr., U. L.; Anais do $12^{\circ}$ Congresso Brasileiro de Catálise, Angra dos Reis, Brasil, 2003.

94. Souza, M. F.; Batista, P. S.; Regiani, I.; Libório, J. B. L.; Souza, D. P. F.; Mater. Res. 2000, 3, 25.

95. Souza, M. F.; Yamamoto, J.; Anais da $4^{a}$ Reunião Anual da SBPN, São Carlos, Brasil, 1996.

96. Souza, M. F.; Yamamoto, J.; Soares, R. M.; Anais do $12^{\circ}$ Congresso Brasileiro de Ciência e Engenharia dos Materiais, Águas de Lindóia, Brasil, 1996.

97. Naskar, M. K.; Chatterjee, M.; J. Eur. Ceram. Soc. 2004, 24, 3499.

98. Chandrasekhar, V.; Nagendran, S.; Samiksha, G. T.; Andavan, G. T. S.; Tetrahedron Lett. 1998, 39, 8505.

99. Jahn, S. L.; Gratieri, E.; Gustavo Paraginski, G.; Ronaldo Hoffmann, R.; Foletto, E. L.; Portugal Jr., U. L.; Anais do XIX Congresso Regional de Iniciação Científica e Tecnológica em Engenharia, Curitiba, Brasil, 2004. 